\title{
Effectiveness of Using Infographics as an Approach for Teaching Programming Fundamentals on Developing Analytical Thinking Skills for High School Students in the City of Makkah in Saudi Arabia
}

\author{
Najwa Al-Mohammadi \\ Dr., Faculty of Education \\ Department of Curricula and Teaching Methods \\ University of Jeddah \\ P.O. Box (15758), Jeddah 21454, Saudi Arabia
}

Tel: 96-612- 683-5270 Ext. $300 \quad$ E-mail: nalmohammadi@kau.edu.sa

Received: January 11, 2017 Accepted: February 21, $2017 \quad$ Published: February 28, 2017

doi:10.5296/gjes.v3i1.10854 URL: http://dx.doi.org/10.5296/gjes.v3i1.10854

\begin{abstract}
The current study aims at investigating the effectiveness of using infographics as an approach to teach the programming fundamentals on developing analytical thinking skills for high school students in the city of Makkah in Saudi Arabia. The study is based on the two-group quasi-experimental design. Participants were 64 girls at the 1st secondary school in Makkah. They were divided into an experimental group comprising of 32 students and a control group comprising also of 32 students. The programming unit was taught to the experimental group using the educational infographics strategy while the control group was taught using the traditional way of instruction. The researcher designed the lessons of the unit based on an infographics form. She designed the analytical thinking test to measure several of the analytical thinking skills. The researcher also used the following statistical methods: t-test for independent samples, Black's Gain Ratio to measure effectiveness. The study results pointed out the effectiveness of using infographics strategy as an approach to teach the programming fundamentals on developing analytical thinking skills.
\end{abstract}

Keywords: Infographics, Programming fundamentals, Analytical thinking skills, Visual representations, Saudi Arabia 


\section{Introduction}

Teaching and learning process is one of the most important educational processes which comprehensively cares from achieving educational objectives all the way up to assessment. Due to the fact that it is a highly complicated process in terms of both nature and procedures, it is often observed that each student has a unique learning style that is formed by having a specific learning pattern used for gaining knowledge from the educational experiences presented to them. Such favored learning patterns ought to be highly considered by students, teachers, as well parents as they are crucial for making the best use of them to improve means of instructions in addition to knowledge acquisition by the students. Recognizing effective learning patterns makes the learning process more effective, economical, efficient, easier, and continuous (Gaines, 2012). A teacher can thus utilize such patterns to offer educational experiences using appropriate methods which are favored by students. The visual pattern in both learning and teaching domains is considered to be one of the most important approaches that ought to be focused on at our schools (Hyerle, 2009); especially at the primary stage due to the fact that its importance lies in its ability to lead to general improvement in the student's progress level. Nelson Company, one of the leading Internet research companies, has asserted that children aged between 2 and 11 years watched an average amount of 118 minutes of videos on Internet daily. Teenagers aged between 12 and 17 years old watched an average amount of 132 minutes daily, while adults who are older than 18 years watched an average amount of 99 minutes daily (Lin \& Polaniecki, 2009). Shafie, Janier, and Wan-Ahmad (2009) conducted a study which aimed at detecting the importance of visual representations and the students' perceptions towards it as a mean of instruction which reinforces learning concepts through graphs and cartoons that attract attention for learning Maths using a multimedia program. Results indicated that students interact more effectively when using visual representation in learning Math. The researcher used the infographic strategy as a visual pattern for teaching because of the importance of such pattern which is highly preferred by many learners. Moreover, it has a great potential in developing learners' thinking skills. That is why it became one of the major teaching objectives in all science majors (Al-Ba'aly, 2013). The researcher studied the effectiveness on one of the most important thinking skills; analytical thinking, which is highly considered by many researchers and thinkers for its relation with other operations like problem-solving, critical and scientific thinking (Newberry, 2011; Nuangchalerm \& Thammasena, 2010). Many researchers, working in scientific education and teaching science, paid a great attention to develop students' abilities to think analytically as reflected in the study of (Siribunnam \& Tayraukham, 2009) which assured the effectiveness of some teaching strategies in developing students' analytical thinking skills.

Despite such consideration with analytical thinking, some studies (Harby, 2009; Sabry, 2009; Wongsri \& Nuangchalerm, 2010) noticed a decline in the students' analytical thinking level at the preparatory stage. These studies attributed such decline to many factors including that syllabi with their current content are limited in improving analytical thinking skills as they only focus on the cognitive part (Panasan \& Nuangchalerm, 2010). In addition, the content nature and presentation method do not give actual chances for practicing analytical thinking skills. Beyer (2001) stressed the necessity of working on stimulating habits of the brain and 
improving cognitive and thinking skills. He suggested including these skills in the educational activities of the syllabus in order to be a part of the procedural aims of daily topics. He assured practicing them regularly in class as simple tasks that can be applied on more complicated ones until the brain gets used to them and be part of it.

\subsection{Problem of the Study}

Since the world has recently become more accumulative in the sense of information, we feel bored while receiving and dealing with such a huge amount of data. Hence, the need for such infographic designs emerged as they have a vital role in simplifying such information and making such data processing much easier and faster. As for teaching the fundamentals of programming as a modern science for the student who do not have prior experience that enables the student to learn better, I believe that teaching the visual approach first makes reading much faster. It fosters information in the students' minds and enables them to read it easily and analyzing data smoothly in an attractive way (Shaltout, 2014). The research problem may be stated in the following question:

What is the effectiveness of using infographics as an approach to teach the fundamentals of programming in developing secondary stage students' analytical thinking skills in the city of Makkah in Saudi Arabia?

\subsection{Hypothesis of the Study}

There are no statistical differences at $(\alpha \leq 0.01)$ level between the secondary stage students' mean scores in the experimental and control groups on the pre-post application of the analytical thinking test in favor of the experimental group.

\subsection{Objectives of the Study}

The research aims at recognizing the effectiveness of using infographics as an approach to teach the fundamentals of programming on developing secondary stage students' analytical thinking skills in the city of Makkah.

\subsection{Significance of the Study}

1) This research may attract supervisors and teachers in general, and computer teachers in particular to the need of varying teaching strategies.

2) The research emphasizes the importance of acquiring analytical thinking skills through visual learning.

3) The research may help computer teachers to overcome obstacles of teaching in general and those of teaching programming in particular.

4) Stressing the necessity of varying the teaching approaches and students' learning styles.

5) Assuring the importance of applying a sense of interest and entertainment on the educational process by provoking students through using interesting educational figures and designs. 


\section{Macrothink}

Global Journal of Educational Studies

ISSN 2377-3936

2017, Vol. 3, No. 1

6) Evoking the students' motivation by using new methods of learning which are based on visual figures.

7) Attracting curricula planners and developers to the necessity of activating the visual approach to shape the content of computer curriculum in accordance with teaching approaches.

8) Attracting the researchers' attention to conduct similar researches on other courses at different stages.

9) This research, as far as I know, is one of the pioneered researches which used infographics as an approach for teaching the fundamentals of programming.

\subsection{Delimitations}

The are several delimitations for this study including:

a. Time: Second term of the academic year 2014/2015

b. Place: Makkah City, Saudi Arabia

c. Participants: First secondary students in the city of Makkah

1) The research application is limited to applying educational infographics on a programming unit chosen from $1^{\text {st }}$ secondary computer course.

2) The research is limited to developing some analytical thinking skills including (identifying properties - differentiating between similarities and differences Comparing and contrasting - categorizing- Predicting- identifying cause and effect).

\subsection{Definitions of Terms}

Effectiveness: It is defined as the effect of experimentation as an independent factor on the dependent factors. Such effect is defined as an impact of one or more independent factor on one or more dependent factors. Such effect is calculated statistically using Eta square (Shahatta \& El-Najjar, 2003). Operationally, in this study, the effectiveness refers to the statistical effect on the dependent variable; the students' progress in learning the fundamentals of programming in terms of skills and information acquired after using the independent variable (infographics) while teaching.

Infographic is the art of transferring information and complicated data into cartoons which are much easier for perception and recognition. It does not require reading much information and more texts which leads to effective visual interaction (Eissa, 2014). This art is also called interactive data visualization and information design. It might be represented using this equation; Information + Graphic = Info graphic (Shaltout, 2014). Operationally, in this study, infographic is the art of visualizing and transferring information and data used in programming into expressive figures which can easily understood.

Analytical Thinking Skills: Al-Ba'aly (2013) defined analytical thinking skills as a mental process that students perform when they face a perplexing situation or a problem. They 
perform some mental skills like; defining features and qualities, differentiating between similarities and differences, classifying, predicting, defining cause and effect, forming a standard. They collect the most possible amount of facts, information, and incidents. They make a minute check of ideas, items, and situations and plans cautiously before taking any decisions or reaching mental conclusions through such facts and information. Operationally, analytical thinking skills are the mental ability which enables a student to analyze programming concepts through defining features and qualities, differentiating between similarities and differences, comparing and contrasting classifying, rearranging, setting priorities, and following serials.

\section{Literature Review and Previous Studies}

Sudakov, Bellsky, Usenyuk, and Polyakova. (2014) conducted a study which aimed at designing educational infographics which calls for integrating Mathematics with modern climate science. This type of integration leads students to employ Mathematical theories in understanding climate processes. Researchers used the descriptive method; they offered a series of electronic infographic posters which explained topics related with Mathematics together with oceans and the climate. University lectures were designed to provide students with realistic examples on how to integrate mathematics with climate science. Researchers designed a questionnaire for a sample of students in the Mathematics and natural sciences departments to know their opinion about their usage of infographics in the educational process. The questionnaire highlighted the fact that the most important educational difficulties in the traditional way. Researchers clarified that all these difficulties are related with modifying visual properties and that they can be solved using infographics. Results of the questionnaire indicated very clearly the importance of infographics in the educational process. It is particularly important in natural sciences such as chemistry, physics, biology, mathematics, and theoretical computer sciences. Results also stressed the benefits and importance of infographics related with mathematics and climate sciences, in particular.

Hafeth (2013) conducted a study which aimed at recognizing the effectiveness of using the visual approach along with the aid of a computer to develop second grade, preparatory school female students' sense of place. The researcher used the experimental research design. The study sample consisted of 90 female students at second grade, preparatory school at "Al-Haram preparatory school for girls" in Cairo, Egypt. They were divided into an experimental group of (46) students and a control group of (44) student. The researcher prepared a student book according to the visual learning approach together with two compact disks comprising videos, a flash memory used in teaching, and a test to measure the level of the sense of place to reach requested results. Results indicated that teaching the unit according to the visual learning approach with the help of the computer which had a strong effect on developing each skill of place sense skills.

Coleman (2010) stressed how far primary level school teachers use charts in their educational practices at Alabama University in USA. The researcher used the descriptive design and used the questionnaire to reach desired results. Results showed an increase in teachers' usage of charts which included most educational practices. 
Shafer (1996) conducted a study which aimed to discover the relationship between the learning approach and the level of academic achievement. The researcher used experimental design. The experiment was operated on grade nine students in one of the rural areas in Louisiana state in U.S.A. The researcher divided the students into (audio-visual- sensorymixed). Results referred that audio learners represent the vast majority of learners. They represent the least mark in the mathematics achievement test while students who used the visual learning style got the highest grades among the rest of the groups.

\section{Theoretical Framework}

\subsection{Infographics}

\subsubsection{The First Axis/ Graphic Design}

As we explore sculptures and ancient drawings that have existed in history for hundreds and thousands of years, we recognize that graphic designs have an ancient repertoire which draws back to the prehistoric period. At that time, humans thought deeply about the ambiguous natural phenomena and represented such thoughts in the form of signals, statues, or religious rituals. After some phases, graphic design reached its current state. It became an independent science taught in a number of international universities. A graphic designer became well respected worldwide. The reason behind is that a designer can transfer pictures from someone's mind and represents it in a professional innovative interesting way using consistent colors and lines (El-Araby, 2008).

\subsubsection{Graphic Design Foundations}

El-Araby (2008) mentioned that these foundations represent the main vocabulary used for expression. There are some foundations for successful graphic design including:

1) Unity: It means that the designed elements are compatible. All elements are shared together in a specified outlined relation.

2) Stability: Designs lie in the center. Sizes become equal while designing as if they are separated by vertical and horizontal separators. As instability creates a feeling of unrest while watching a design.

3) Rhythm: The tone and flow creates a sense of rhythm as repetition is a main foundation in visual design as it is a mutual element between visual and audio arts.

4) Movement: Some people tend to repeat same items in different positions to denote that they are moving. Such movement might be continuous or indirectly implied.

\subsubsection{Design Types}

A design might be formed using one of these ways:

1) Two-dimensional design (2D): All design programs are able to produce two dimensions' shapes. They depend on visual harmony and innovative purposeful production.

2) Three-dimensional design (3D): It is a design which depends on vacuum space. It can be 
viewed from different angles within varied perspectives. It can shape a mental vision of the design or figure as if it is made by the viewer. That is why it differs from the two-dimensional design in terms of reshaping figures.

\subsubsection{Infographics; Pros \& Characteristics}

Eissa (2014) and Simiciklas (2012) mentioned infographics characteristics in the following main points:

1) Simplifying hard and complicated information-based on visual effects to be easier for reading and understanding.

2) Transferring data and information from its traditional form as represented by letters and numbers into interesting figures and drawings.

3) Using visual scanning to minimize time consumed in reading such massive amount of written data and information.

4) The effectiveness of using infographics art in marketing via social media to attract customers.

5) Ease of publication and distribution via social networks.

6) Enforcing the process of saving information as far as possible.

The most prominent characteristics of infographics can be defined in the following points; El-Araby (2008):

- It is a visual explanation which helps in understanding and finding information easily.

- It is a visual graphical representation which integrates vocabulary and figures in a smooth way.

- It is self-explanatory and it does not require further explanation and clarification.

- It makes the understanding process faster and consistent.

- It is internationally understood.I

- It only focuses on the most important points.

- It is interesting for readers.

\subsubsection{Types of Infographics}

Shaltout (2014) mentioned that infographics could be divided into two types; each has specific characteristics and programs for implementation:

\subsubsection{First: Static Graphics}

They include media or static description that could be printed or distributed on internet websites. The content of static infographics comprises photographed informative explanation of a specific topic chosen by the owner of the idea. Example: The info graphic pressed on a 
research website called (market research) which expresses parents' opinions about their children's back to school.

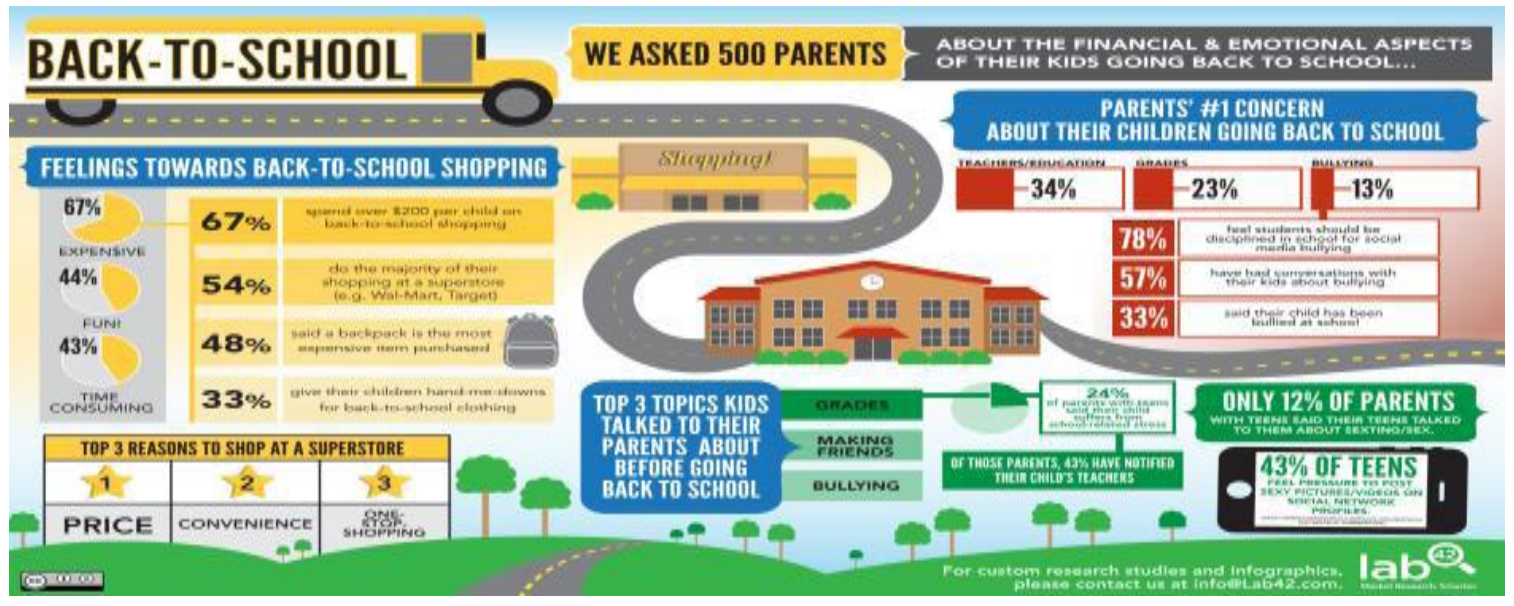

Figure 1. Fixed infographics

\subsubsection{Second: Motion Graphics}

They are two types:

The first type: Representing video recordings in a usual way and clarifying data and information using motion graphics to represent some facts and concepts on the video script. Yet, this type is not often used.

The second type: It is in the form of designing data, information, and clarification with the total usage of motion graphics. This type requires a lot of innovation together with choosing expressive movements to help in the production in an interesting and creative way. When you make a full scenario, you get a final product of this type. This is the most commonly used type right now.

\subsection{Usage of Infographics}

Recently, infographics has spread throughout many fields in life. It has been used in media, education, awareness initiatives, entertainment, environment protection, etc.

\subsubsection{In Education}

As indicated previously, the concept of infographics, can be easily used in visual presentation of information. Knowledge constructed in academic courses could be applied in the visual design form represented in the static and motion infographic. Such learning schemes improve the human levels of understanding and recognition as well as imagination. In addition, they have the ability to relate the various elements of different educational subjects together. The usage of infographics while producing electronic content in a fast and easy way is widely spread. The importance of using infographics in education has increased as learners' desire to understand certain topics by viewing rather than reading, has increased. 


\section{Macrothink}

Global Journal of Educational Studies

ISSN 2377-3936

2017, Vol. 3, No. 1

\subsubsection{In Marketing}

Graphics advertisement has recently widespread in the marketing field on most websites and social media networks as they are easily shared and widely distributed. They are more attractive for clients or target groups. The largest companies have recently been presenting their visions and objectives by designing advertisements using infographic to attract their target groups (Eissa, 2014 \& Bazara'a, 2013).

\subsubsection{Infographics Designing Programs}

By using computer applications with features for editing photos and figures like:

a. Adobe Illustrator which is a leading program in infographic design field due to the fact that it is considered one of the most flexible programs which produces attractive designs.

b. Adobe Photoshop: It is one of the most popular editing programs in the world. It represents data using nice photographs but it does not compare Adobe Illustrator's level of flexibility.

By using Web 2.0 web sites to construct simple infographics such as:

- Piktochart

- Nkscape

- Tableau

- Easelly

- Infogram

- List of tools

\subsubsection{Steps in Designing Infographics}

Shaltout (2014) mentioned that designing infographics passes through a number of important steps that should be clear for whoever wants to offer a clear and outstanding infographic. They include the following important steps:

- Choosing the main idea.

- Preliminary drawing.

- Choice of main headings and sub headings.

- Being prudent to keep design parts as one unit.

- Choice of colors.

- Revising designs.

- Representing the whole content.

- Assuring drawings authenticity. 
- Final production

3.2.5 The Difference between Infographics and Mind Maps

Infographics is considered to be a type of drawing designs. They integrate several types of drawings like cartoons, graphs, charts...etc. This is most similar to mind maps. Bazara'a (2013) compared between info graphic and mind maps in the light of the following questions:

1) Who prepares it? A mind map is prepared by learners as they do it themselves while an info graphic is prepared by a specialized graphic designer.

2) Who reads it? It is hard for anyone to read a mid-map other than the one who made it. Meanwhile, a large number of people can read an infographic.

3) What is it based on? Mind maps rely on the student's understanding of the map elements and how they are related together. It means that mind maps are subjective. On the other hand, a graphic designer designs infographics in a way that can be easily read. He employs the principles of visual design to receive and explain data easily.

4) What is the educational value for infographics? Mind maps are considered as tools of constructive education and a method of interactive learning while infographics are considered to be one of learning resources.

5) What are the required skills for designing it? The production of mind maps only needs a pen and a piece of paper while infographics need designing skills and professional tools.

\subsection{Analytical Thinking: The Second Axis}

\subsubsection{Thinking Concept}

Thinking concepts are varied in a way which integrates more than one concept so it can be stated that thinking is:

- An inner state of auto monologue which continues while performing a task, or listening to someone, or watching something.

- A mental process which occurs inside the human brain and thinking is not necessary associated with problem solving.

- A serial of unseen activities performed in the human brain while facing a stimulus received from one or more human sense.

- A thoughtful investigation of an experience in order to achieve a specific aim. This aim might be decision making, understanding, planning, judging things, problem-solving, or performing a task (Habib, 2003).

\subsection{Analytical Thinking Concept}

Analytical thinking is defined as central, collective, and converging thinking. It is considered as one of the most important types of thinking that humans can acquire by practicing and training. Analytical thinking represents an upper mental process which includes cognitive and 
mental planning. This way, "It is an embedded mental activity that cannot be directly noticed. Yet, it could be inferred from its effects" (Hussam El-Din, 2011, p. 17). It can be also defined as the ability which leads individuals to analyze situations of interest into smaller components to be suitable for performing any further analytical operations (Reber, 1990). It considers analyzing all what is complicated or combined into their authentic smaller components and later uses these components for total perception (De Bono, 1998).

\subsubsection{Characteristics of Analytical Thinking}

1) It is considered to be a main step in the stages of scientific thinking.

2) It seeks for dividing ideas into smaller components without giving priority to any component.

3) It leads to one solution as it is controlled by specific rules.

4) It leads individuals to a state of mental stability.

5) It changes quantitively and qualitatively according to the maturity of individuals' experiences (Katamy, 1990) \& (Abdel-Monim, 2009).

\subsubsection{Components of Analytical Thinking}

It consists of complicated components such as:

- A cognitive component represented by experiences, facts, and concepts related with the subject content.

- A perceptive component represented initially by awareness and then by attention and importance.

- A sentimental component which comprises personal factors and abilities, intrinsic properties, motivation, concentration, and self-confidence.

- A coordinating component which comprises mental coordination together with Kinesthetic and neurological response (Abdel-Monim, 2009).

\subsubsection{Skills of Analytical Thinking}

Hussain (2007), Al-Utoom (2007), and Katamy (2003) identified the skills that are included in the analytical thinking as follows:

1) Defining attributes or traits: It is the ability to conclude full description and define general attributes of different things.

2) Defining features: It means defining common features and outstanding traits of something.

3) Performing observation: Testing characteristics and suitable procedures which rationalize and helps in the process of gathering information.

4) Differentiating between similarities and differences: Discriminating things or ideas from 
different perspectives.

5) Comparing and contrasting: Comparing between two things from different perspectives.

6) Accumulation and classification: The ability to classify items and similar elements into groups.

7) Rating: How to rate information, classify and divide it into groups.

8) Building a standard: Defining and evaluating the most beneficial standards that can be used to assess the importance of elements or items.

9) Arranging, setting priorities, and making serials: Putting items or events in chronological order according to value or time of occurrence of specific events.

10) Viewing relations: Comparing between events and ideas to define the system applied in two or more operations.

11) Finding types: Recognizing the private differences between two or more characteristics in a relation which leads to a repeated pattern.

12) Guessing/foreseeing/predicting: Using well-known knowledge, comparing, and contrasting, specific relations to define or predict similar events in the future.

13) Defining cause and effect: defining causes or high results of previous actions and events which are more effective.

14) Performing measurement: defining relations among familiar items or events and similar ones in a new situation.

15) Generalization: It is the ability to construct a number of phrases and sentences which are derived from the relations among related concepts.

\subsubsection{The Importance of Improving Analytical Thinking Skills}

Amer (2007) mentioned that the importance of improving analytical thinking skills draws back to what has been stated briefly in previous studies about the obstacles related to analysis. Such obstacles are related to compositional and analytical thinking as it compares to problem solving. Researchers have identified some of these obstacles as follows:

1) Difficulty in separating the main problems from the mixed ones. It becomes more difficult when we deal with a problem in its compound form or care about minute partial details. It becomes difficult to discriminate what is important from the most important. May be a sub-problem is important, yet it is not substantial.

2) Difficulty in the real reception of minute relations among the elements of the problem. This leads an individual to fail in recognizing relations and adapting with emergency changes occurring with relations between perceptions and concepts related with a problem. Moreover, it hinders full awareness.

3) Isolating a problem from the context. This makes us unable to take different sides of the 
problem into account and leads to less recognition. Practice on mental flexibility helps to overcome such kind of obstacles.

4) Neglecting the employment of some senses in the recognition process. Most observations rely on the sense of hearing and sight, nevertheless that the rest of senses perform a great role.

It has been clear from what has been previously stated and discussed that lacking analytical skills leads to other obstacles in problem-solving situations.

\section{Research Design}

The researcher used a quasi-experimental design of two groups which is based on experimentation and testing of a specific hypothesis. It decides the relationship between using the independent variable (using infographics in education) and the dependent variable (developing analytical thinking skills) by controlling all variables other than the one that is of interest for the researcher.

\subsection{Research Sample and Community}

Sample: The research sample consisted of a group of $1^{\text {st }}$ year secondary school students at $A l$ Rabeaa School in the city of Makkah in Saudi Arabia.

Community: The research community consists of $1^{\text {st }}$ year secondary school students in the city of Makkah in Saudi Arabia.

\subsection{Research Tools and Materials}

The research depended on the following materials:

- Infographics for the first unit (An Introduction to Programming) from the computer course taught during the second term at $1^{\text {st }}$ secondary by using some of its programs as clarified in appendix (3).

In order to analyze the results, the research required preparing the following tools:

1) Analytical thinking test which measures some analytical thinking skills of $1^{\text {st }}$ year secondary students after studying the unit (An Introduction to Programming) using the suggested method.

Preparing the test required formulating behavioral objectives as clarified in appendix (1).

Table 1. Relative weight of topics

\begin{tabular}{|l|l|l|l|}
\hline Serial & Topic & No of pages & $\begin{array}{l}\text { Relative weight according to } \\
\text { the importance of the topic }\end{array}$ \\
\hline 1 & Concept of programming & 3.5 & $43.75 \%$ \\
\hline 2 & Importance of programming & 1 & $12.5 \%$ \\
\hline 3 & Divisions of programming languages & 3.5 & $43.75 \%$ \\
\hline & Total number of pages and percentage & 8 & 100 \\
\hline
\end{tabular}




\section{$\triangle$ Macrothink}

Global Journal of Educational Studies

ISSN 2377-3936

2017, Vol. 3, No. 1

Table 2. Specifications of analytical thinking test

\begin{tabular}{|c|c|c|c|c|c|c|c|c|c|}
\hline \multirow[t]{2}{*}{ Topics } & \multirow[t]{2}{*}{$\begin{array}{l}\text { Questions } \\
\text { and marks }\end{array}$} & \multicolumn{5}{|c|}{ Skills levels } & \multirow{2}{*}{$\begin{array}{c}\text { Total } \\
\text { questions } \\
\text { prediction }\end{array}$} & \multicolumn{2}{|c|}{$\begin{array}{c}\text { Relative weight } \\
\text { of Topics }\end{array}$} \\
\hline & & $\begin{array}{l}\text { Comparing } \\
\text { and } \\
\text { contrasting }\end{array}$ & $\begin{array}{c}\text { Defining } \\
\text { traits }\end{array}$ & $\begin{array}{l}\text { Defining } \\
\text { the cause }\end{array}$ & Analysis & $\begin{array}{c}\text { Differentiating } \\
\text { between }\end{array}$ & & & \\
\hline $\begin{array}{l}\text { Concept of } \\
\text { programing }\end{array}$ & questions & 2 & 4 & ---- & ---- & --- & --- & 6 & $43.75 \%$ \\
\hline $\begin{array}{l}\text { Importance of } \\
\text { programming }\end{array}$ & questions & ---- & ---- & 1 & ----- & ----- & ----- & 1 & $12.5 \%$ \\
\hline $\begin{array}{c}\text { Divisions of } \\
\text { programming } \\
\text { languages }\end{array}$ & questions & ----- & --- & --- & 1 & 1 & 1 & 3 & $43.75 \%$ \\
\hline Total questions & & 2 & 4 & 1 & 1 & 1 & 1 & 10 & \\
\hline $\begin{array}{c}\text { Relative weight } \\
\text { of objectives }\end{array}$ & & $20 \%$ & $40 \%$ & $10 \%$ & $10 \%$ & $10 \%$ & $10 \%$ & & $100 \%$ \\
\hline
\end{tabular}

The items of the test were constructed according to the analytical thinking skills implied in the unit, the final version is clear at Appendix (2).

Test validity (content validity): The researcher offered the test in its preliminary form to a group of specialists in teaching computer (computer teachers) to calculate the test validity. The jury members were 5 to ensure the suitability of each paragraph of the test, its clarity, suitability for objectives, and linguistic content.

Test reliability: The researcher ensured the reliability of the test by observing the students' performance and assessing them in each skill. The level of perfection is referred to as 1 if the student is perfect and 0 in case of imperfection. The same process was repeated after one week. Pearson correlation factor between the students' marks in the two previous observations was calculated at 0.88 which means that the test is reliable and ready for application.

\subsection{Research Procedures}

The researcher conducted the study according to the following steps:

1) Reviewing the literature and previous studies related to the visual approach, its strategies, charts, infographics, and analytical thinking skills.

2) Analyzing the fourth unit (An Introduction to Programming) in the $1^{\text {st }}$ year secondary school computer course in order to:

- Designing educational subject (the lessons) on the infographics educational form using its special programs.

- Preparing the study tool (analytical test)

3) Being prepared to apply the study by dividing the sample into an experimental and a control group. 
4) Explaining the programming unit using infographics strategy for the experimental group and teaching the control group using the traditional way.

5) Applying the achievement test which measures analytical thinking skills in the pre-application for the two groups (control and experimental) and then post application on only the experimental group in order to measure its effectiveness on developing $1^{\text {st }}$ secondary students' analytical thinking skills.

6) Explaining and analyzing results.

\section{Research Results}

To test the verification of the study hypothesis which states that "there are no statistical differences at the $\alpha$ level of $\leq 0.01$ between the average of the $1^{\text {st }}$ year secondary school students' grades in the pre and post application of the analytical thinking test in favor of the experimental group", t-test for independent samples was applied to discover differences between the experimental and control group in the post application of the analytical thinking test. The researcher reached the following results:

Table 3. T-value, significance of differences between average marks of the two groups (experimental and control) in the post application of the test

\begin{tabular}{|c|c|c|c|c|c|c|}
\hline Group & Number & Average & $\begin{array}{c}\text { Standard } \\
\text { deviation }\end{array}$ & $\mathrm{t}$ value & $\begin{array}{c}\text { Degree of } \\
\text { freedom }\end{array}$ & $\begin{array}{c}\text { Level of } \\
\text { significance }\end{array}$ \\
\cline { 1 - 5 } Experimental & 32 & 6.437 & 2.28 & 3.618 & 62 & 0.001 \\
\hline Control & 32 & 4.28 & 2.47 & & & \\
\hline
\end{tabular}

It is identified from the previous table that $t$-value of the experimental effect between the two groups equal (3.6) which indicates no statistically significance difference at the $\alpha$ level of $\leq$ 0.01 . This result assures that the research null hypothesis is accepted. That there are statistical differences at the $\alpha$ level of $\leq 0.01$ among the students' grades in the pre and post test of the analytical thinking test in favor of the experimental group for secondary stage students in the city of Makkah. This result can be explained by infographics as an educational effective way of simplifying concepts. It has an interesting attractive method that can reach the students' minds faster than traditional methods. This type of visual presentation stresses the importance of visual style in education and its effectiveness in attracting learner's attention and concentration. This result is consistent with the studies of Hafeth (2013), Coleman (2010), Shafer (1996) and Sudakov et al. (2014).

Blake's gain ratio was calculated know the effectiveness of using infographics as an approach to teach the fundamentals of programming in order to develop the analytical thinking skills of a sample of secondary stage students in the city of Makkah by using the following equation:

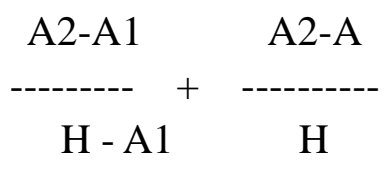




\section{Macrothink}

Where A1 refers to the mean of students' scores in the pre test

Where A2 refers to the mean of students' scores in the post test

$\mathrm{H}$ refers to the highest mark of the test

This indicates that the ratio of Blake's gain is 1.218. This value lies on the acceptable region defined by Blake. Therefore, infographics could be used as a teaching approach to teach the fundamentals of programming in order to develop secondary stage students' analytical thinking skills in the city of Makkah and be effective to a great extent.

\section{Recommendations}

In light of results, the researcher recommends the following:

1) Training computer teachers on designing lessons using educational infographics in teaching.

2) Activating infographics methods or any other method implying visual approach strategies to teach the fundamentals of programming.

3) To carry out more research studies on using infographics as an approach to teach the fundamentals of programming and measure its effectiveness in other variables.

\section{References}

Abdel- Monim, T. (2009). A Proposed Program for Teaching Analytical Thinking and its Effectiveness on Developing Reading Comprehension and Awareness of Thinking Processes for Preparatory School Students. Curriculum and instructions, Egyptian Association for Curriculum and instructions, 144.

Al-Ba'aly. (2013). Effectiveness of a Proposed Unit at Science According to the Perspective of Costa and Calik for Mind Habits on Developing Analytical Thinking and Scientific Tendencies for the First-Grade Preparatory School Students in the Kingdom of Saudi Arabia. Practical Education Magazine, 5(116).

Al-Utoom, A. et al. (2007). Developing Thinking Skills. Al-Sera Publication House. Amman, Jordan.

Amer, A. (2007). Analytical Thinking; Ability, Skill and Technique. College of Arts, Cairo University, Egypt.

Bazara'a, M. (2014). Can We Use Infographics in Education? Retrieved from https://goo.gl/iQZjgc

Beyer, B. (2001). What Research Suggests About Teaching Thinking Skills. In A. Costa (Ed.), Developing the Mind: A Book for Teaching Thinking. Alexandria, VA: Association for Supervision and Curriculum Development.

Coleman, J. (2010). Elementary Teachers, Instructional Practices Involving Graphical Representations. Journal of Visual Literacy, 29(2), 198-222. 
http://dx.doi.org/10.1007/s10972-010-9204-1

De Bono, E. (1998). The Court Program for Teaching Thinking. Translation: Nadia Al Soror et al. Arab Thought House for Printing and Publications. Amman, Jordan.

Eissa, M. (2014). What is the Infographic? Definition, Tips and Free Tools. Retrieved from http://xn------lzecaacca1 agqu6awd7etd9hde5br5cm6bt6bf

El-Arabi, R. (2008). Infographic Design. Amman, Jordan, Electronic Copy. Retrieved from https://kenanaonline.com/files/0011/11257/GraohicDesign.pdf

Gaines, K. (2012). Why Are Students Not Learning on the School Bus? The Future of Learning Outside the Classroom in American Schools, iUniverse.

Habib, M. A. (2003). Teaching Thinking at the Information Age (Approach, Concepts, Keys, Theories, and Programs) (1st ed.). Arab Thought House for Printing and Publications, Cairo, Egypt.

Hafeth, A. M. (2013). Effectiveness of Using Visual Approach in Teaching Mathematics Using Computers on Developing Spatial Sensation for Preparatory School Students. Journal of Mathematics Education, 16.

Hussain, T. (2007). The Comprehensive in Thinking Skills. Amman, Jordan: De Bono House for Printing and Publications.

Hussam- EL-Din, L. A. (2011). Teaching Some Environmental Issues Using Scientific Arguments for Stimulating the Ability of Scientific Interpretation and Analytical Thinking by the $1^{\text {st }}$ Grade Secondary School Students. Practical Education, 4(14).

Hyerle, D. (2009). Visual Tools for Transforming Information into Knowledge. Thousand Oak Publications.

Katamy, N. (2003). Teaching Thinking for Children (1st ed.). Amman, Jordan: Arab Thought House for Printing and Publications.

Katamy, Y. (1990). Children Thinking; Its Development and its Way of Teaching. Amman, Jordan: Arab Thought House for Printing and Publications.

Lin, C. C., \& Polaniecki, S. (2009). From Media Consumption to Media Production: Applications of YouTube ${ }^{\mathrm{TM}}$ in an Eighth-Grade Video Documentary Project. Journal of Visual Literacy, 28(1), 92-107.

Newberry, P. (2011). Critical Thinking: A User-S Manual. Boston-Clark Baxter, USA.

Nuangchalerm, P., \& Thammasena, B. (2009). Cognitive Development, Analytical Thinking, and Learning Satisfaction of Second Grade Students learned through Inquiry-based Learning. Asian Social Science, 5(10), 82. http://dx.doi.org/10.5539/ass.v5n10p82

Panasan, M., \& Nuangchalerm, P. (2010). Learning Outcomes of Project-Based and Inquiry-Based Learning Activities. Journal of Social Sciences, 6(2), 252-255. 
Reber, A. (1985). Dictionary of Psychology. The Penguin Book Publishers.

Shaffer, J. (1996). A Study of the Relationship Between Learning Modality Strength and Mathematics' Achievement of Ninth-Grade Students from a Rural Mississippi Delta School. Ed.D Thesis, Delta State University, Cleveland-USA.

Shafie, A., Janier, J., \& Wan-Ahmad, W. (2009). Visual Learning in Application of Integration, Visual Informatics: Bridging Research and Practice. First International Visual Informatics Conference, November, pp. 832-843.

Siribunnam, R., \& Tayraukham, S. (2009). Effects of 7-e, KWL and Conventional Instruction on Analytical Thinking, Learning Achievement and Attitudes Toward Chemistry Learning. Journal of Social Sciences, 5(4), 279-282. http://10.3844/jssp.2009.279.282

Smiciklas, M. (2012). The Power of Infographics. Indiana, USA.

Sudakov, I., Bellsky, T., Usenyuk, S., \& Polyakova, V. (2014). Mathematics and Climate Infographics: A Mechanism for Interdisciplinary Collaboration in the Classroom. Physics Education, 1-8. http://10.1080/10511970.2015.1072607

Wongsri, P., \& Nuangchalerm, P. (2010). Learning Outcomes between Socio-scientific Issues-Based Learning and Conventional Learning and Activities. Journal of Social Sciences, 6(2), 240-243.

\section{Appendix 1.}

\section{Behavioral Objectives}

\begin{tabular}{|l|c|}
\hline \multicolumn{1}{|c|}{ Behavioral Objective } & The Measured Skill \\
\hline $\begin{array}{l}\text { 1. To differentiate between the programmer and the user of } \\
\text { the program }\end{array}$ & Comparing and contrasting \\
\hline $\begin{array}{l}\text { 2. To compare between ready-made programs and developed } \\
\text { programs. }\end{array}$ & Comparing and contrasting \\
\hline 3. To define the characteristics of programming entry orders. & Defining characteristics \\
\hline 4. To define the characteristics of programming output orders. & Defining characteristics \\
\hline $\begin{array}{l}\text { 5. To define the characteristics of programming computer } \\
\text { orders. }\end{array}$ & Defining characteristics \\
\hline $\begin{array}{l}\text { 6. To define the characteristics of conditionals in } \\
\text { programming. }\end{array}$ & Defining characteristics \\
\hline $\begin{array}{l}\text { 7. To define the characteristics of repeated orders in } \\
\text { programming. }\end{array}$ & Defining characteristics \\
\hline 8. To define the benefit of programming for the computer & Defining cause and effect \\
\hline 9. To define the high-level programming languages. & Analysis \\
\hline $\begin{array}{l}\text { 10.To compare procedural programming with human } \\
\text { programming }\end{array}$ & $\begin{array}{c}\text { Differentiating between } \\
\text { similarities and }\end{array}$ \\
\hline 11.To predict the future of programming languages & Prediction \\
\hline
\end{tabular}




\section{Appendix (2)}

\section{Test of Analytical Thinking Skills}

Student's name Year: $1^{\text {st }}$ secondary

Time allotted for the test: 30 minutes

\section{In the Name of Allah}

Part I. Choose the correct answer by drawing a circle (2 Marks):

1. $1 \ldots \ldots . .$. is the one who writes orders to the computer to solve a specific problem.
a. User
b. programmer
c. administrator user of the computer
d. a technician

2. ................Programs are defined as general previously written programs that can be bought from the market.
a. developed
b. borrowed
c. ready-made
d. executive

Part II. Compare between procedural programming and programming with objects in terms of: (2 marks)

\begin{tabular}{|l|l|l|}
\hline In terms of & $\begin{array}{l}\text { Procedural } \\
\text { programming }\end{array}$ & $\begin{array}{l}\text { Programming with } \\
\text { objects }\end{array}$ \\
\hline Controlling the track of program application & & \\
\hline Constructing a preface for users & & \\
\hline Relating data bases & & \\
\hline Applying the program & & \\
\hline
\end{tabular}

B. Justify the following: We can say that computers without programming are useless. (One mark)

Part III.

A. Classify the following languages into the language of procedural programming and the language of programming objects. (Two marks).
1. Java
2. $\mathrm{C}$
3. $\mathrm{C}++$
4. Basic

B. Complete using the suitable order (2 Marks):

1. Command ............ presents information resulting from executing the program.

2. Command ............: symbolize for the reapplication of a number of orders.

3. Command .............: receives data that will be processed by the system.

4. Command ............: performs the mathematical processes processed by the program. 


\section{Macrothink}

Global Journal of Educational Studies ISSN 2377-3936 2017, Vol. 3, No. 1

C. In the light of the information you have, predict how programming languages would be like in the future. (one mark)

\section{Best of Luck}

Distribution of the Critical Thinking Skills on the questions of the test:

Question one. Measures the skill of comparing and contrasting.

Question two:
A. Measures the skill of differentiating between similarities and differences.
B. Measures the skill of defining characteristics.
C. Measures the skill of prediction.

Question three:
A. Measures the classifications skills.
B. Measures properties specifications skills.
C. Measures prediction skills.

\section{Appendix 3}

\section{Unit Lessons Designed Using Infographics}
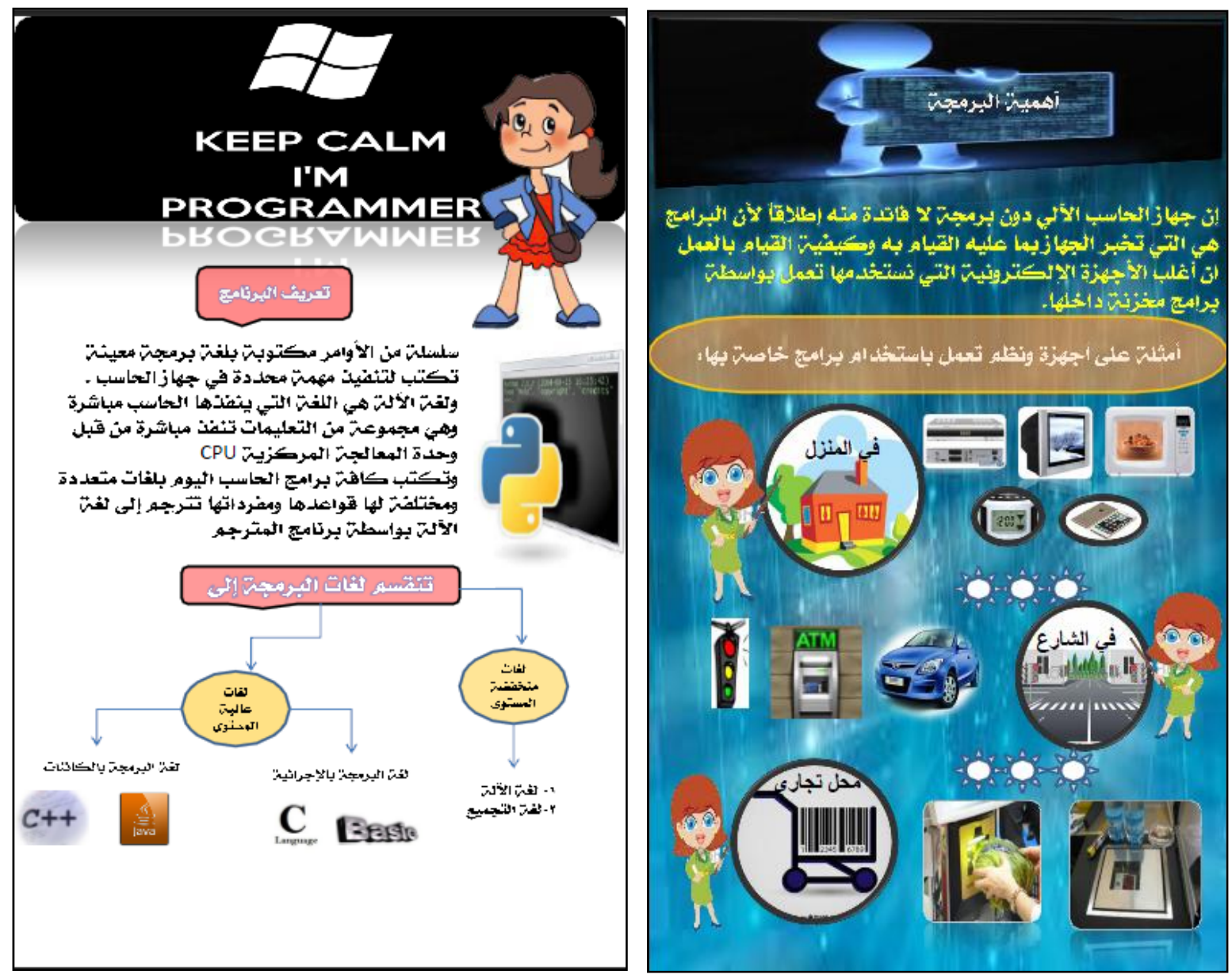

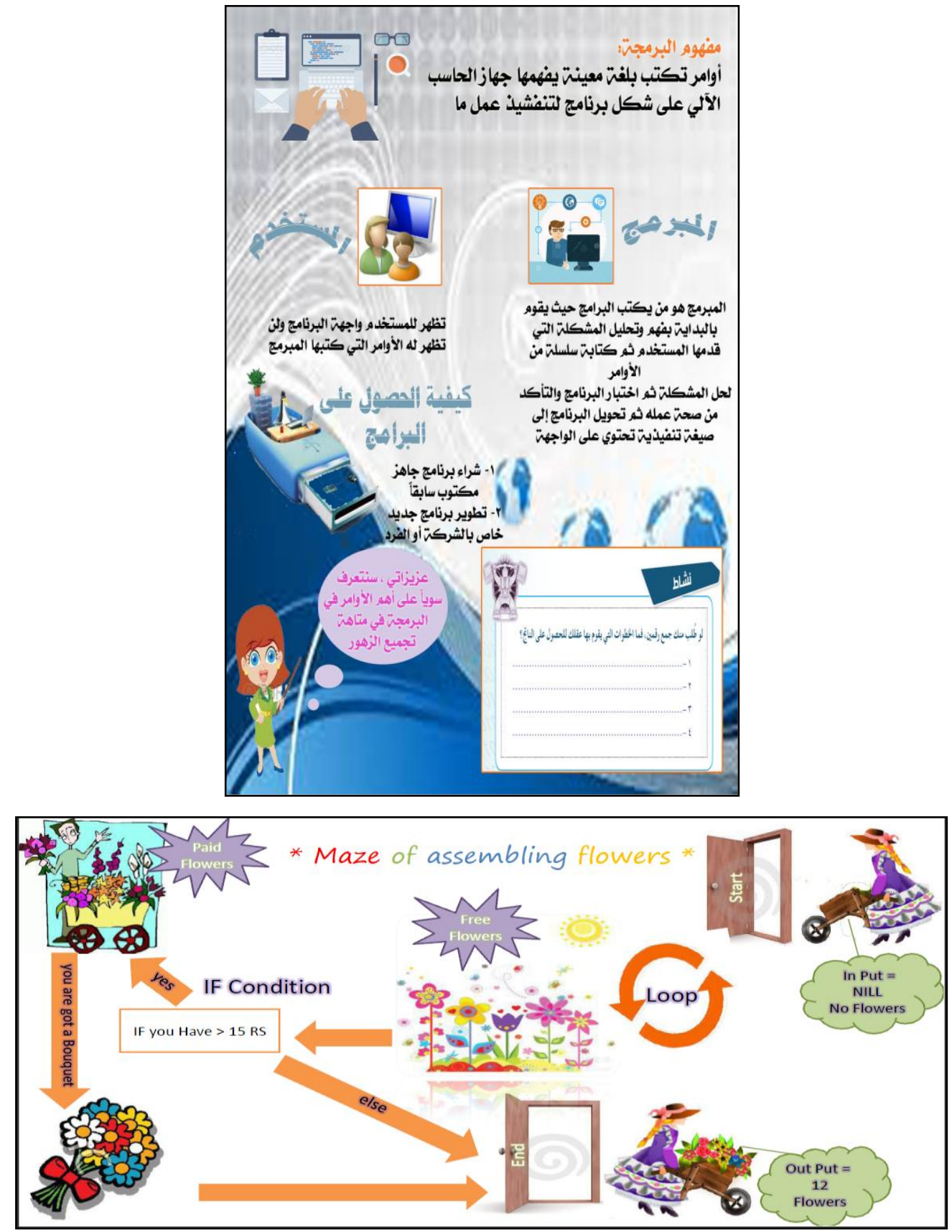

\section{Copyright Disclaimer}

Copyright for this article is retained by the author(s), with first publication rights granted to the journal.

This is an open-access article distributed under the terms and conditions of the Creative Commons Attribution license (http://creativecommons.org/licenses/by/3.0/). 